Alkol içermeyen iki

farklı ağız gargarasının

geçici restorasyon

materyallerinin renk

değişimine etkisi

\section{The effect of two different \\ mouthrinses \\ without alcohol on \\ color change of \\ temporary restoration materials}

\author{
Dr. Öğr. Üyesi Burcu Diker \\ İstanbul Okan Üniversitesi, Diş Hekimliği Fakültesi, \\ Protetik Diş Tedavisi A.D., İstanbul \\ Orcid ID: 0000-0001-5367-9369
}

\section{Dr. Öğr. Üyesi Bahar Elter}

İstanbul Okan Üniversitesi, Diş Hekimliği Fakültesi, Protetik Diş Tedavisi A.D., İstanbul

Orcid ID: 0000-0002-8971-6819

Geliş tarihi: 27 Ağustos 2020

Kabul tarihi: 12 Ocak 2021

doi: $10.5505 /$ yeditepe.2021.63644

\section{Yazışma adresi:}

Dr. Öğr. Üyesi Burcu Diker

İstanbul Okan Üniversitesi, Diş Hekimliği Fakültesi, Protetik Diş Tedavisi A.D.

Tuzla Kampüsü, 34959 Akfırat, Tuzla, İstanbul

Tel: +902166771630

Fax: 02166771647

E-posta:dtburcuf@gmail.com ; burcu.diker@okan.
ÖZET

Amaç: Mevcut çalışmanın amacı iki farklı ağız gargarasında bekletilen dört farklı geçici restorasyon materyallerinin renk değişimlerinin karşılaştırıımasıdır.

Gereç ve Yöntem: Silikon kalıp yardımıyla bis-akril kompozit rezin ve polimetil metakrilat (PMMA) içerikli dört geçici restorasyon materyalinden $14 \mathrm{~mm}$ çapında ve $2 \mathrm{~mm}$ yüksekliğinde toplam 84 örnek hazırlandı. Hazırlanan örnekler distile suda 1 hafta bekletildikten sonra başlangıç renk değerleri ölçüldü. Distile su (kontrol) ve ağız gargaralarına (Listerin ve Klorhex) maruz bırakılacak şekilde 3 alt gruba ayrıldı $(n=7)$. Günde 2 dakika kullanım ile 1 yıllık kullanıma denk gelecek şekilde toplam 12 saat sıvilarda bekletildi ve tekrar renk ölçümleri yapıldı. İki ölçüm arasındaki renk değişim değerleri CIEDE2000 formülü ile hesaplandı ve iki yönlü varyans analizi (ANOVA) ile incelendi $(a=05)$.

Bulgular: Geçici materyallerin renk değişimleri materyal $(p=, 000)$ ve gargara $(p=, 004)$ tipinden anlamlı olarak etkilendi. Materyalden bağımsız olarak gargaraların renk değişimi üzerine etkisi değerlendirildiğinde Klorhex ile distile su arasında anlamlı bir farklılık görülmezken, Listerin grubunda en yüksek renk değişikliği gözlendi. Sadece materyallerin etkisi değerlendirildiğinde bis-akril kompozit rezin grubunda (Acrytemp ve Protemp 4), PMMA grubuna (Temdent ve Imident) göre daha fazla renk değişimi gözlemlendi $(p<, 05)$.

Sonuç: Bu çalışmada kullanılan geçici restorasyonların renk değişimi, materyal ve gargaralara bağlı olarak değişim gösterdi. En az renk değişimi PMMA grubundan Temdent'te görülürken, Klorhex Listerin'den daha az renk değişimine neden oldu. Bununla birlikte tüm gruplardaki renk değişimleri klinik olarak kabul edilebilir aralıktaydı.

Anahtar kelimeler: Renk, dental materyaller, gargara SUMMARY

Aim: The aim of the present study was to compare to the discoloration of four different temporary restoration materials immersed into two different oral rinses.

Materials and Method: $14 \mathrm{~mm}$ diameter, $2 \mathrm{~mm}$ thick, a total of 84 samples were prepared from the bis-acryl composite resin and polymethyl methacrylate (PMMA) based four different temporary restoration materials. After the prepared samples were stored in distilled water for one week, the initial color data was measured. The specimens were divided into three subgroups: Klorhex, Listerine, and distilled water (control) $(n=7)$. The specimens were immersed in liquids for a total of 12 hours as be equivalent to 1 year for 2 minutes daily use. Then, the color data were measured again. The color change values between data were calculated using CIEDE2000 formula and analyzed by two-way analysis of variance (ANOVA) $(a=.05)$.

Results: The color changes of temporary materials were significantly affected by material $(p=.000)$ and mouthrinse $(p=.004)$ type. Only when the effect of mouthrinses on color change was evaluated, there was no significant difference 
between distilled water and Klorhex. The highest color change was observed in the Listerine group. The higher color change was observed in the bis-acryl composite resin group (Acrytemp and Protemp4) compared to the PMMA group (Temdent and Imident) $(p<.05)$.

Conclusion: The color change of the temporary restorations used in the present study differed depending on the material and mouthrinse types. The least change was observed in Temdent, while Klorhex caused less change than Listerine. However, color changes in all groups were within the clinically acceptable range.

Keywords: Color, Dental Materials, Mounthrinse

\section{GíRiş}

Sabit protez uygulamaları çoğunlukla, diş preparasyonu sonrasında daimi restorasyonun teslimine kadar akrilik ya da kompozit rezinden üretilmiş geçici restorasyonların kullanımını gerektirir. Geçici restorasyonlar, daimi restorasyonların tesliminden önceki süreçte dişlerin pozisyonel stabilizasyonunu, çiğneme fonksiyonunun devamlıı̆ını ve dişlerin dış etkenlerden korunmasını sağlar. Özellikle, planlanan tedavi uzun süre geçici restorasyon kullanımını gerektiyorsa, geçici restorasyonların hem estetik hem de fiziksel olarak ağızda devamlılığını sürdürmesi gerekir. Geçici materyallerin renk stabilitesi, özellikle estetik bölgedeki restorasyonlarda asıl önemli konudur. Geçici materyallerdeki algılanabilir renklenmeler, hastanın memnuniyetsizliğine ve restorasyonun yenilenme intiyacına, dolayısıyla da ek tedavi masrafına neden olabilmektedir. Geçici materyallerdeki renk değişimleri kimyasal yapısı veya maruz kaldığı dış faktörlerle ilişkilidir. Yapısında bulunan stabilizatörler, kimyasal olarak indüklenen renk değişimini belirli bir ölçüde azaltmış olsa da, geçici materyaller sıvıları emerek ve boyanarak renk değişimine uğramaktadırlar.' Renklenme miktarları, tamamlanmamış polimerizasyon, su absorpsiyonu, kimyasal reaktivite, hastanın diyeti ve oral hijyeni gibi faktörlere bağlı olarak değişebilir. ${ }^{2}$ Bunların dışında renk değişimine neden olan dış kaynaklı faktörler arasında ağız gargaralarının da olduğu, çalışmalarda gösterilmiştir. ${ }^{3-5}$ Ağız gargaraları, oral hijyenin devamlılığının sağlanması ve bakteri kolonizasyonunu önlemek için sıklıkla kullanılır. Klorheksidin diglukonat, periodontal hastalığı ve diş çürüğünü azaltan yaygın olarak kabul gören bir antibakteriyel ajandır. Bununla birlikte mine ve restoratif materyallerde boyanma, diş taşı oluşumu ve geçici hoş olmayan tat gibi olumsuz özellikleri de görülmüştür. ${ }^{6}$ Listerin, gingivitisin tedavisi için anti-plak ajan olarak kullanılan bir ağız gargarasıdır. Asıl olarak içerdiği esansiyel yağlar mentol, ökaliptol, timol ve metil salisilat olarak sıralanabilir. Literatürde ağız gargaralarının kompozit rezinlerde ${ }^{7}$, minede ${ }^{8}$, biyoseramiklerde ${ }^{9,10}$ ve akrilik materyallerde ${ }^{4,11}$ renk değişimine neden olduğu gösterilmiştir. Ağız gargaralarının alkol içeriklerindeki artışın, biyoseramik materyallerde renk değişimini arttırdığını gösteren çalışmaların ${ }^{9}$ yanı sıra, rezin kompozitlerde alkol içermeyen klorheksidinin alkol içeren Listerin'e göre daha fazla renk değişimine yol açtığını gösteren çalışmalar ${ }^{10} \mathrm{da}$ vardır. Literatürde alkol içeriği ve renk değişimi ilişkisi ile ilgili yeterli bir kanıt bulunmamaktadır.

Sabit geçici protez için kullanılabilen materyaller polimetilmetakrilat (PMMA), üretan dimetakrilat (UDMA), polietil metakrilat, polivinil metakrilat, bis-akril kompozit rezin materyallerdir. ${ }^{12}$ Bu materyaller kimyasal, ışık ya da hem ışık hem de kimyasal yöntemlerle polimerize olabilir. ${ }^{5}$ Geçici restorasyonlar, ağız ortamında direkt ya da laboratuvarda indirekt yöntemlerle üretilebilir. ${ }^{13}$ PMMA ve bis-akril kompozit rezin materyaller protetik diş hekimliğinde sıklıkla kullanılan materyallerdir. Bu materyallerin, bileşimin homojenliği, yüzey pürüzlülükleri ve suyu absorbe etme miktarı gibi faktörlere bağlı olarak renklendirici sıvılarda renk stabilitelerinin değiștiği gösterilmiștir."11

Renk değişimleri Uluslararası Aydınlatma Komisyonu'nun (Commission internationale de l'éclairage-CIE) belirlediği CIELAB formülü ile hesaplanabilir. Bu sistemde hesaplanan değer ne kadar büyük olursa renk farkı da o kadar büyük olur ve sonuç olarak insan gözü için daha algılanabilir seviyeye ulaşır. Hesaplanan ve algılanan renk farklııkları arasındaki doğrulamayı iyileştirmeyi amaçlayan komisyon, renk farkı değerlendirmesinde aydınlatma ve görme koşullarının etkisinin hesaba katıldığı parametreler ile CIEDE2000 formülünü oluşturmuştur. ${ }^{14}$

Literatürde geçici restorasyon materyallerinin renk stabilitelerinin değerlendirilmesi için renklendirici içecekler ve ağız gargaraları kullanılmıştır. Bununla birlikte kullanılan renklendirici sıvılar ve geçici restorasyonların tipine bağlı olarak farklı sonuçlar elde edilmiştir. Bu çalışmada, alkol içermeyen Klorhex ve Listerin ağız gargaralarının klinikte sıklıkla kullanılan 4 farklı geçici restorasyon materyalin renk stabilitesine etkisini incelemek amaçlanmıştır. Bu amaca yönelik olarak çalışmanın başlangıç hipotezi, geçici restorasyon materyallerinde meydana gelen renk değişimlerinin kullanılan materyallere ve ağız gargaralarına bağlı değişiklik göstermeyeceği olarak belirlenmiştir. 


\section{GEREÇ VE YÖNTEM}

Bu çalışmada bis-akril kompozit rezin (Acrytemp ve Protemp 4) ve PMMA (Temdent ve Imident) içerikli 4 adet geçici restorasyon materyalinin renk değişimi, 2 farklı ağız gargarası (Klorhex ve Listerin) kullanılarak değerlendirilmiştir. Kullanılan materyallere ilişkin içerik ve üretici bilgileri Tablo 1'de yer almaktadır.

Tablo 1. Çalışmada kullanılan materyallerin tipi ve üreticileri.

\begin{tabular}{|c|c|c|}
\hline Ürün & Materyal tipi- içeriği & Oretici Firma \\
\hline Acrytemp & Bis-akril kompozit rezin & Zhermack SpA, Italya \\
\hline Protemp 4 & Bis-akril kompozit rezin & 3M ESPE, Seefeld, Almanya \\
\hline Temdent Classic & PMMA & $\begin{array}{c}\text { Schūtz Dental GmbH, Rosbach, } \\
\text { Almanya }\end{array}$ \\
\hline Imident & PMMA & Imicryl Dental, Konya, Türkiye \\
\hline Klorhex & $\% 0,2$ Klorheksidin diglukonat & Drogsan, Ankara, Türkiye \\
\hline $\begin{array}{c}\text { Listerin Total Care } \\
\text { Zero }\end{array}$ & $\begin{array}{l}\text { Timol, ökaliptol, mentol, metil } \\
\text { salisilat, sodyum florür, } \\
\text { sukraloz, propilen glikol, } \\
\text { sodyum florid, Cl } 16035, \mathrm{Cl} \\
42090\end{array}$ & Johnson and Johnson, İtalya \\
\hline
\end{tabular}

Subaşı ve ark.'nın ${ }^{15}$ yaptığı çalışmanın sonuçlarına göre bir yazııım programı ile $(\mathrm{G} *$ Power 3.1.9.4) güç analizi yapılııştır. Minimum örnek sayısı \%95 güç, 1,25 etki büyüklüğü ve 0,05 a değeri ile 3 olarak hesaplanmıştır. Çalışmanın gücünü arttırmak için, silikon kalıplar (Resim 1A) kullanılarak her grup için $2 \mathrm{~mm}$ yüksekliğinde disk şeklinde standardize 7 örnek hazırlanmıştır. Önceki çalışmalarda örneklerin ölçülen yüzey genişliklerinin $10 \mathrm{~mm}$ ile $15 \mathrm{~mm}$ arasında değiştiği görülmüştür. ${ }^{16-18}$ Kullanılan silikon kalıplar yardımıyla örneklerin çapları 14 mm olarak üretilmiştir. Üretici firmaların talimatları doğrultusunda PMMA grubundaki materyaller, uygun oranda toz ve likit karıştırılarak hazırlanırken bis-akril kompozit rezin grubundakiler tabancalı aparatları ile kalıp içerisine enjekte edilmiştir. Kalıp içerisine yerleştirilen örnekler üzerine siman camı ile hafif baskı uygulanarak fazla materyalin taşması sağlanmıştır (Resim 1B). Polimerizasyonu tamamlanan örnekler kalıplardan ç।karılıp elde edilen örneklerin boyutlarının kontrolü dijital kumpas ile sağlanmış ve toplamda 84 örnek elde edilmiştir (Resim 1C). Yüzey standardizasyonu için örneklerin her yüzeyi silikon karbid su zımparaları (800 ve 1000 grid'lik) ile toplamda 1 dakika boyunca zımparalanmış ve 1 hafta boyunca distile suda bekletilmiştir.

Her materyal grubu maruz bırakılan gargara tipine göre rastgele olarak 2 alt gruba ve 1 kontrol grubuna ayrılmıştır. Başlangıç renk değerlerinin ölçülmesi için gargaraların günde 2 dakika kullanımıyla toplam 1 yıllık zamanı simule etmek için materyal grupları, gargaralara ve distile suya 12 saat boyunca maruz bırakılmıştır. ${ }^{3}$ Bu süre sonunda örnekler distile su ile yıkanıp nazikçe kurutulmuştur. Renk ölçümleri için Vita Easyshade dijital spektrofotometre (VITA Zahnfabrik H. Rauter GmbH\& Co. KG, Bad Sackingen, Almanya) kullanılmışır (Resim 1D). Her örnek için üç tekrarlı ölçüm yapılmış ve renk değişikliklerini belirlemek için $L *$, $a * v e b *$ parametrelerinin ortalama değerleri CIEDE2000 formülüne uygulanarak kullanılmıştır. $L$ rengin parlaklığını (0:siyah, 100:beyaz), a kırmızılık yeşilliğini (-60:yeşil, +60:kırmızı), b sarılık maviliğini (-60:mavi, +60:sarı) ifade eder. KL, KC ve KH parametrik değerleri 1 olarak ayarlanmıştır. ${ }^{19}$ Materyal tamamen renk stabilitesine sahip ve hiç renk değişimi göstermediyse $\Delta \mathrm{E}_{00}=0$ olarak bulunur.

$\Delta \mathrm{E}_{00}$ değerleri 1,30'dan yüksekse algılanabilir, 2,25'in altındaysa klinik olarak kabul edilebilir olarak nitelendirilmiştir. ${ }^{20,21}$ Ölçümler, solüsyonlara koyulmadan önce ve 12 saat sonra beyaz renkli zemin üzerinde yapılmıştır. ${ }^{15,18}$ 2 farklı zamanda yapılan ölçümler arasındaki $\Delta \mathrm{E}_{00}$ renk değişim değerlerinin hesaplanması için aşağıdaki formül kulanılmıştır:

$\Delta \mathrm{E} 00=\left[\left(\Delta \mathrm{L}^{\prime} / \mathrm{KLSL}\right) 2+\left(\Delta \mathrm{C}^{\prime} / \mathrm{KcSc}\right) 2+\left(\Delta \mathrm{H}^{\prime} / \mathrm{KHSH}\right) 2+\mathrm{RT}\right.$ $\left.\left(\Delta \mathrm{C}^{\prime} / \mathrm{KCSC}\right)\left(\Delta \mathrm{H}^{\prime} / \mathrm{KHSH}\right)\right] 1 / 2$

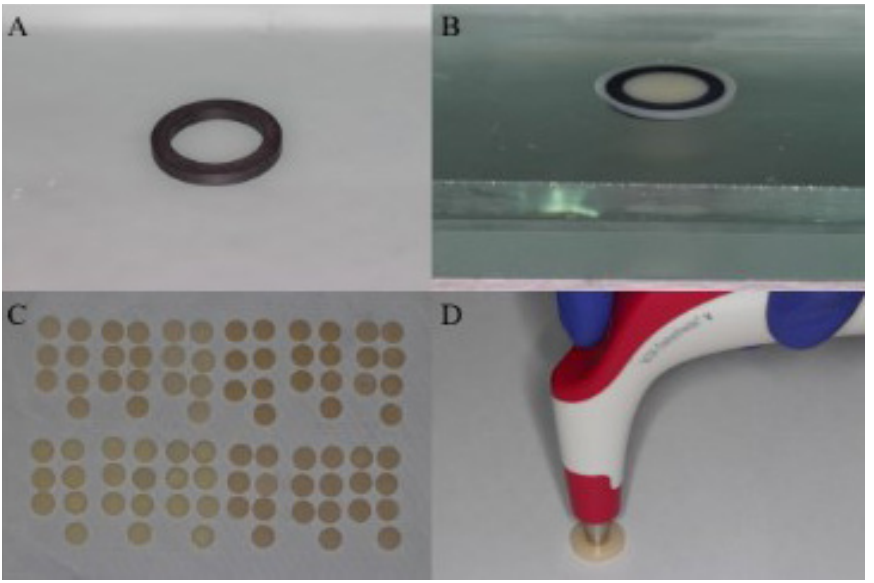

Resim 1. A. Silikon kalıp, B. Silikon kalıbın iki siman camı arasına yerleştirilmesi le fazla materyalin taşmasının sağlanması, C. Toplam 12 grup için elde edilen disk şeklinde örnekler, D. Renk ölçümlerinin Vita Easyshade ile gerçekleştirilmes

Renk değişiminde materyal tipinin ve gargara solüsyonlarının etkisini değerlendirmek için bir istatistik yazıımı (SPSS 22.0, SPSS Inc, Chicago, IL, ABD) ile iki yönlü varyans analizi (ANOVA) testi uygulanmış ve çoklu karşılaştırmalar için Tukey testi kullanılmıştır. İstatistiksel olarak anlamlıık sınırı 0,05 olarak ayarlanmıştır.

\section{BULGULAR}

İki yönlü varyans analizi, hem materyalin $(p=<, 001)$ hem de solüsyonun $(p=, 004)$ renk değişimi üzerinde istatistiksel olarak anlamlı etkilerinin olduğunu göstermiştir. Materyal ile solüsyon arasındaki etkileşim istatistiksel olarak anlamlı bulunmamıştır $(\mathrm{p}=, 082)$ (Tablo 2 ).

Tablo 2. Renk değişim değerlerinin iki yönlü ANOVA sonucu.

\begin{tabular}{|c|c|c|c|c|c|}
\hline & $\begin{array}{c}\text { Kareler } \\
\text { toplamı }\end{array}$ & $\begin{array}{c}\text { Serbestlik } \\
\text { derecesi }\end{array}$ & $\begin{array}{c}\text { Kareler } \\
\text { ortalaması }\end{array}$ & $\mathrm{F}$ & $\mathrm{P}$ \\
\hline Materyal & 3,825 & 3 & 1,275 & 13,750 &, $000^{*}$ \\
\hline Solüsyon & 1,101 & 2 &, 551 & 5,938 &, $004^{*}$ \\
\hline $\begin{array}{c}\text { Materyal } x \\
\text { Solüsyon }\end{array}$ & 1,093 & 6 &, 182 & 1,965 &, 082 \\
\hline
\end{tabular}

* İstatistiksel olarak anlamlı farklılık $(\mathrm{p}<, 05)$ 
Tablo 3. CIEDE2000 formülü ile hesaplanan renk değișimlerinin ( E00) ortalama ve standart sapma değerleri.

\begin{tabular}{|l|l|l|l|l|l|}
\hline $\begin{array}{l}\text { Materyal/ } \\
\text { Solüsyon }\end{array}$ & Acrytemp & Protemp & Temdent & Imident & Toplam \\
\hline Klorhex & $0,51 \pm 0,46$ & $0,72 \pm 0,28$ & $0,39 \pm 0,29$ & $0,32 \pm 0,10$ & $0,49 \pm 0,33^{\mathrm{A}}$ \\
\hline Listerin & $1,08 \pm 0,48$ & $1,07 \pm 0,22$ & $0,25 \pm 0,05$ & $0,58 \pm 0,42$ & $0,75 \pm 0,48^{\mathrm{B}}$ \\
\hline Distile su & $0,73 \pm 0,24$ & $0,66 \pm 0,34$ & $0,35 \pm 0,15$ & $0,36 \pm 0,20$ & $0,52 \pm 0,29^{\mathrm{A}}$ \\
\hline Toplam & $0,78 \pm 0,46^{*}$ & $0,81 \pm 0,33^{\mathrm{N}}$ & $0,33 \pm 0,19^{\mathrm{b}}$ & $0,42 \pm 0,28^{\mathrm{b}}$ & \\
* İstatistiksel olarak anlamlı farklılı ( $\mathrm{p}<, 05)$
\end{tabular}

Tablo 3'de materyal ve solüsyon gruplarında görülen renk değişimlerinin değerleri yer almaktadır. $\Delta \mathrm{E}_{00^{\prime}}$ ortalama ve standart sapma değerleri ile ifade edilmişsir. En fazla renklenme materyalden bağımsız olarak Listerin'e $(0,75 \pm 0,48)$ maruz bırakılmış gruplarda görülürken, solüsyondan bağımsız olarak en fazla renklenen materyal de Protemp $(0,81 \pm 0,33)$ olarak bulunmuş ve iki değer de algılanabilir değerden $\left(\Delta \mathrm{E}_{00}>1,30\right)$ daha düşük olarak saptanmışıtır.

Renk değişiminde materyal faktörü değerlendirildiğinde Acrytemp ile Protemp grupları arasında anlamlı bir farkllık gözlenmezken ( $p=976)$, Acrytemp ile Imident $(p=, 002)$, Acrytemp ile Temdent $(p=, 000)$, Protemp ile Imident $(p=, 000)$ ve Protemp ile Temdent $(p=, 000)$ arasinda istatistiksel olarak anlamlı bir farkllık tespit edilmiștir. Imident ve Temdent grupları arasında renk değişiminde önemli farkllıklar bulunmamıştır $(\mathrm{p}=, 771)$.

Solüsyonun renk değişimi üzerine etkisi değerlendirildiğinde distile su ile Klorhex grupları arasında istatistiksel olarak anlamlı bir fark gözlenmezken $(p=, 886)$, Listerin ile distile su $(p=, 022)$ ve Listerin ile Klorhex $(p=, 006)$ grupları arasında anlamlı farklııklar görülmüştür.

\section{TARTIŞMA}

Mevcut çalışmada farklı ağız gargaralarının ve materyal tiplerinin renklenme üzerine etkisi incelenmiştir. Çalışmanın sonuçlarına göre; geçici restorasyon materyallerinde oluşan renklenmenin kullanılan ağız gargaralarına ve materyallere bağlı farklılık göstermeyeceği hipotezi reddedilmiştir. Materyallere ve gargaralara bağlı olarak renklenmede anlamlı farklııklar bulunmuştur. Fakat materyal ve gargara etkileşiminin renk üzerinde anlamlı bir etkisi görülmemiştir.

Dental materyallerdeki renk değişiminin sayısal olarak değerlendirilebilmesi için spektrofotometre renk ölçüm cihazı sıklıkla kullanılmaktadır. Spektrofotometre, yüksek tekrarlanabilirlik ve hassasiyet gibi avantajlar sunar. ${ }^{22}$ Spektrofotometre ile elde edilen ton, parlaklık ve doygunlukla ilişkili değerler CIE'nin belirlediği formüllerde kullanılarak renk değişimleri hesaplanabilir. CIE, 2001 yılında CIELAB renk karakterizasyon sistemi formülünü geliştirerek CIEDE2000 olarak güncellenen bir formül ileri sürmüştür. ${ }^{23} \mathrm{Bu}$ iki formülün birbirleriyle korele olduğunu gösteren bir çalışmanın ${ }^{24}$ yanı sıra bir çalışmada insan gözünün algıladığı renk değişimlerini, CIEDE2000 formülünün CIELAB formülünden daha iyi yansıttığı gösterilmiştir. ${ }^{25} \mathrm{Bu}$ nedenle, bu çalışmada spektrofotometre kullanılmış ve renk değişimleri CIEDE2000 formülüne göre hesaplanmıştır. Spektrofotometre ile renk ölçümleri beyaz ve siyah zemin üzerinde gerçekleştirilebilir. Bununla birlikte daha önce yapılmış olan çalışmalarda siyah zeminin, arkada diş yapısının bulunmadığı Sınıf IV kompozit restorasyonların klinik durumunu taklit ettiği, beyaz zeminin ise Sınıf II ve III gibi en az 1 diş duvarının bulunduğu restorasyonların ya da veneerlerin klinik durumunu taklit ettiği belirtilmiştir. ${ }^{26,27} \mathrm{Bu}$ çalışmada diş dokusu ile desteklenecek geçici restorasyon materyalleri test edildiği için ölçümler beyaz zemin üzerinde yapılmıştır.

Bayındır ve ark. ${ }^{12}$, metil metakrilat ve bis-akril kompozit rezin geçici materyallerinin renk değişimlerini değerlendirmek için 3 farklı içecek solüsyonuna maruz bırakmıştır. Metil metakrilat rezinin renklenmeye karşı bis-akril kompozit rezinden daha dirençli olduğunu göstermişlerdir. Turgut ve ark. ${ }^{11}$ ise ağız gargaralarının bis-akril kompozit rezin ve PMMA esaslı geçici restorasyon materyallerinin renklenmesi üzerine etkilerini incelemiş ve benzer olarak PMMA esaslı materyalde (Temdent) (maruz bırakılan gargaralara bağlı olarak 3,02 $\pm 0,6$ ile 3,52 $\pm 0,2$ aralığında), bis-akril kompozit rezin materyallerden (4,68 \pm 0,6 ile 5,38 $\pm 0,3$ aralığında) daha az renk değişikliği gözlemlemiştir. Bu sonuçlarla uyumlu olarak bu çalışmada da PMMA esaslı Temdent $(0,33 \pm 0,19)$ ve Imident'in $(0,42 \pm 0,28)$, Acrytemp $(0,78 \pm 0,46)$ ve Protemp'den $(0,81 \pm 0,33)$ anlamlı olarak daha az renklenme gösterdiği bulunmuştur. Bunun nedeni olarak, akrilik esaslı materyallerin daha homojen yapı gösterirken kompozit esaslı materyallerin daha heterojen yapıda olması gösterilebilir. Gargaraların renklendirici bileşimlerinin absorbsiyonu ve daha derin penetrasyonu, heterojen yapıdaki materyalde daha fazla oluşabilir. Bununla birlikte kompozit materyaldeki reakte olmamış çift bağlar da bu renklenmenin artmasına neden olabilir. ${ }^{28}$ Turgut ve ark.'nın ${ }^{11}$ çalışmasında ve bu çalışmada bulunan renklenme değerlerinin farklılığında, gargaralarda bekletme sürelerinin ve renk değişiminin hesaplanmasında kullanılan formüllerin (CIELAB ve CIEDE2000) farklı olması etkili olabilir. Bu çalışmada bulunan tüm renk değişimleri, algılanabilir değerin $\left(\Delta \mathrm{E}_{00}>1,30\right)$ altında gözlemlenmiştir.

Literatürdeki bir çalışmada klorheksidin, benzidamin hidroklorür ve hibrid bir ağız gargarasının geçici akrilik materyalindeki renk değişimine etkisi incelenmiş ve klorheksidinin kontrol (distile su) grubu ile istatistiksel olarak bir fark göstermediği bulunmuştur. ${ }^{3}$ Bu sonuçla uyumlu olarak mevcut çalışmada da klorheksidin ile distile su grubu arasında anlamlı bir renk değişimi gözlenmemiştir. Turgut ve ark. ${ }^{11}$ ıın çalışmasında, günde 2 dakika gargaraya maruz bırakılacak şekilde toplam 3 hafta sonundaki renk değişimlerinin (yapay tükürükte bekletilerek) , incelenen 4 ağız gargarasına (klorheksidin, benzidamin hidroklorür, hibrid ve listerin) bağlı olarak farklılık göstermediği bulunmuştur. Hibrid ağız gargarası, klorheksidin ve benzidamin hidroklorürün birleşimi olarak tanımlanmıştır. ${ }^{3} \mathrm{Bu}$ çalışmada ise 
Listerin'e 12 saat boyunca maruz bırakılan materyallerdeki renk değişimi, kontrol grubuna ve Klorhex'e göre anlamlı derecede yüksek bulunmuştur. Sonuçlardaki farklıı̆̆ın, ağız gargaralarında bekletme sürelerinin farklı olması ve bu süreler arasında yapay tükürükte bekletilmesine bağlı olabileceği düşünülmektedir. Materyallerdeki farklılık olarak Turgut ve ark. ${ }^{11}$ ın çalışmasında alkol içerikli listerin kullanıırken, bu çalışmada alkol içermeyen listerin kullanılmıştır. Önceki bir çalışmada, test edilen bilgisayar destekli üretimde kullanılan materyallere bağlı olarak daha düşük alkol içeren ağız gargarasının $(0.49 \pm 0.23$ ile $0.64 \pm$ 0.36 aralığında) yüksek alkol içeren gargaraya (0.48 \pm 0.13 ile $2.54 \pm 0.32$ aralığında) göre daha az renk değişikliğine neden olduğu sonucuna varılmıştır. ${ }^{9}$ Bununla birlikte Lee ve ark. ${ }^{29}$ alkol oranı daha düşük olan Listerin grubunda, daha yüksek olan Listerin grubuna göre daha fazla renklenme gözlemlemiştir. Çeşitli markaların ağız gargaraları, görsel olarak daha çekici hale getirilmek için pembe, mavi ya da yeşil renkte olabilmektedir. Bu çalışmada kullanılan alkol içermeyen pembe renkli Listerin ağız gargarasının daha fazla renklenmeye neden olmasının nedeni renklendirilmiş yapıda olmasıyla da ilişkili olabilir. Renklenmeye içeriğindeki Cl 16035 (Allura kırmızısı AC) ve Cl 42090 (Parlak mavi FCF)'nin neden olabileceği düşünülmektedir. İleride yapılacak çalışmalarda bu içeriklere sahip olmayan farklı Listerin ürünleri ile bu çalışmada kullanılan Listerin'in geçici materyallerdeki renk değişimine etkisi değerlendirilebilir.

Bu çalışma 'in vitro' olarak tasarlanmış ve gerçekleştirilmiştir. Bu nedenle bazı limitasyonlara sahiptir. Klinik pratikte karşılaşılacak olan tükrüğün yıkama ve uzaklaştırma etkisi bu çalışmaya yansıtılmamıştır. Bunun dışında diyet ve materyaldeki aşınma ve buna bağlı pürüzlülüğünün değişmesinin taklit edilmemesi çalışmanın sınırlamaları arasındadır. Bu faktörlerin dahil edildiği bir çalışma düşünülmelidir. Fakat bununla birlikte literatürde karşılaştırılan alkollü ağız gargaralarından farklı olarak alkolsüz ve renklendirici içeriğe sahip ağız gargarasının ve klinikte sıklıkla kullanılan geçici restorasyon materyallerinin kullanılması çalışmanın avantajları arasındadır.

\section{SONUC}

Renk değişimini hem geçici restorasyon materyali hem de ağız gargarası tipi anlamlı derecede etkilemiştir. Bis-akril kompozit rezin grubundaki materyaller, PMMA bazlı materyallerden daha fazla renklenmiştir. Listerin ise Klorhex ve distile suya göre materyallerde daha fazla renk değişimine neden olmuştur. Bununla beraber elde edilen tüm renk değişimi değerleri, klinik olarak kabul edilebilir bulunmuştur $(\triangle \mathrm{E} 00<2,25)$.

\section{KAYNAKLAR}

1. Yannikakis SA, Zissis AJ, Polyzois GL, Caroni C. Color stability of provisional resin restorative materials. J Prosthet Dent 1998;80:533-539.
2. Doray PG, Li D, Powers JM. Color stability of provisional restorative materials after accelerated aging. J Prosthodont 2001;10:212-216.

3. Cal E, Güneri P, Kose T. Digital analysis of mouthrinses' staining characteristics on provisional acrylic resins. J Oral Rehabil 2007;34:297-303.

4. Prasad DK, Alva H, Shetty M. Evaluation of colour stability of provisional restorative materials exposed to different mouth rinses at varying time intervals: an in vitro study. J Indian Prosthodont Soc 2014;14:85-92.

5. Prajapati $P$, Sethuraman $R$, Naveen $Y$, Patel A, Patel J. A comparative analysis of staining characteristics of mouthrinses on provisional acrylic resin: An in vitro study. J Interdiscip Dent 2013;3:167.

6. James $\mathrm{P}$, Worthington HV, Parnell $\mathrm{C}$, Harding M, Lamont $\mathrm{T}$, et al. Chlorhexidine mouthrinse as an adjunctive treatment for gingival health. Cochrane Database Syst Rev 2017;2017:CD008676.

7. Elembaby AES. The effects of mouth rinses on the color stability of resin-based restorative materials. J Esthet Restor Dent 2014;26:264-271.

8. Moreira AD, Mattos CT, De Araújo MVA, Ruellas ACDO, Sant'Anna EF. Chromatic analysis of teeth exposed to different mouthrinses. J Dent 2013;41:e24-27.

9. Soygun K, Varol O, Ozer A, Bolayir G. Investigations on the effects of mouthrinses on the colour stability and surface roughness of different dental bioceramics. J Adv Prosthodont 2017;9:200-207.

10. Derafshi R, Khorshidi H, Kalantari M, Ghaffarlou I. Effect of mouthrinses on color stability of monolithic zirconia and feldspathic ceramic: An in vitro study. BMC Oral Health 2017:17:129.

11. Turgut $\mathrm{S}$, Bagis $B$, Aydogan Ayaz E, Utku Ulusoy $\mathrm{K}$, Han Altintas $S$, et al. Discoloration of provisional restorations after oral rinses. Int J Med Sci 2013;10:1503-1509.

12. Bayindir $F$, Kürklü $D$, Yanikoğlu ND. The effect of staining solutions on the color stability of provisional prosthodontic materials. J Dent 2012;40:e41-46.

13. Naqash TA, Alfarsi M, Hussain MW. Marginal accuracy of provisional crowns using three material systems and two techniques: A scanning electron microscope study. Pakistan J Med Sci 2019;35:55-60.

14. Luo MR, Cui G, Rigg B. The development of the CIE 2000 colour-difference formula: CIEDE2000. Color Res Appl 2001;26:340-350.

15. Subaşı MG, Demir N, Karcı M, Gökkaya Bozkurt M. Farklı geçici materyallerin farklı sıvılarda kısa dönem bekletme sonrası renk ve yüzey pürüzlülük değişiminin incelenmesi. Atatürk Üniv Diş Hek Fak Derg 2019;29:448-454. 16. Ardu S, Rossier I, di Bella E, Krejci I, Dietschi D. Resin composite thickness' influence on $\mathrm{L} * \mathrm{a} * \mathrm{~b} *$ coordinates and translucency. Clin Oral Investig 2019;23:1583-1586. 17. AlGhazali N, Burnside G, Smith RW, Preston AJ, Jarad 
FD. Performance assessment of Vita Easy Shade spectrophotometer on colour measurement of aesthetic dental materials. Eur J Prosthodont Restor Dent 2011;19:168-174. 18. Akay C, Çakırbay Tanış M, Gulverdiyeva M. Coloration of provisional restoration materials: a comparison of the effects of mouth rinses and green tea. Eur Oral Res 2018;52:19-24.

19. Ayaz EA, Ustun S. Effect of staining and denture cleaning on color stability of differently polymerized denture base acrylic resins. Niger J Clin Pract 2020;23:304-309.

20. Sahin O, Koroglu A, Dede DÖ, Yilmaz B. Effect of surface sealant agents on the surface roughness and color stability of denture base materials. J Prosthet Dent 2016;116:610-616.

21. Köroğlu A, Sahin O, Dede DÖ, Yilmaz B. Effect of different surface treatment methods on the surface roughness and color stability of interim prosthodontic materials. J Prosthet Dent 2016;115:447-455.

22. Paul $S$, Peter $A$, Pietrobon N, Hämmerle CHF. Visual and spectrophotometric shade analysis of human teeth. $J$ Dent Res 2002;81:578-582.

23. Sharma G, Wu W, Dalal EN. The CIEDE2000 color-difference formula: Implementation notes, supplementary test data, and mathematical observations. Color Res Appl 2005;30:21-30.

24. Lee YK. Comparison of CIELAB $\triangle E \star$ and CIEDE2000 color-differences after polymerization and thermocycling of resin composites. Dent Mater 2005;21:678-682.

25. Gómez-Polo C, Muñoz MP, Lorenzo Luengo MC, Vicente P, Galindo P, et al. Comparison of the CIELab and CIEDE2000 color difference formulas. J Prosthet Dent 2016;115:65-70.

26. Gregor L, Krejci I, Di Bella E, Feilzer AJ, Ardu S. Silorane, ormocer, methacrylate and compomer long-term staining susceptibility using $\Delta \mathrm{E}$ and $\Delta \mathrm{E} 00$ colour-difference formulas. Odontology 2016;104:305-309.

27. Ardu S, Braut V, Gutemberg D, Krejci I, Dietschi D, et al. A long-term laboratory test on staining susceptibility of esthetic composite resin materials. Quintessence Int 2010;41:695-702.

28. Haselton DR, Diaz-Arnold AM, Dawson DV. Effect of storage solution on surface roughness of provisional crown and fixed partial denture materials. J Prosthodont 2004;13:227-232.

29. Lee JH, Kim SH, Yoon HI, Yeo ISL, Han JS. Colour stability and surface properties of high-translucency restorative materials for digital dentistry after simulated oral rinsing. Eur J Oral Sci 2020;128:170-180. 